\title{
c-Myc promotes tumor proliferation and anti-apoptosis by repressing p21 in rhabdomyosarcomas
}

\author{
JINGHANG ZHANG $^{1 *}$, NA SONG $^{3 *}$, DAN ZANG $^{1}$, JIAN YU $^{1}$, JINSONG LI $^{1}$, \\ WENYU DI ${ }^{1}$, RUINA GUO ${ }^{4}$, WEIXING ZHAO ${ }^{1,2}$ and HAIJUN WANG ${ }^{1,2}$ \\ ${ }^{1}$ Department of Pathology, The First Affiliated Hospital of Xinxiang Medical University; ${ }^{2}$ Department of Pathology; \\ ${ }^{3}$ Department of Molecular Biology and Biochemistry, School of Basic Medical Sciences, Xinxiang Medical University, \\ Xinxiang 453003; ${ }^{4}$ Department of Pathology, Puyang Oilfield General Hospital, Puyang 457000, P.R. China
}

Received December 24, 2015; Accepted January 5, 2017

DOI: $10.3892 / \mathrm{mmr} .2017 .7101$

\begin{abstract}
. v-myc avian myelocytomatosis viral oncogene homolog (c-Myc) is an important member protein of the Myc family that is important in cell cycle progression, apoptosis and tumorigenesis. In the present study, the role of c-Myc in rhabdomyosarcoma (RMS) was assessed. Firstly, expression of endogenous c-Myc and cyclin dependent kinase inhibitor $1 \mathrm{~A}$ (p21) was examined in normal skeletal muscle, RMS specimens and TE671 RMS cells by immunohistochemistry, reverse transcription-quantitative polymerase chain reaction and western blotting. Furthermore, cell cycle progression and apoptosis were assessed in TE671 RMS cells following treatment with a c-Myc inhibitor, 10058-F4. The results demonstrated that c-Myc was overexpressed in clinical RMS tissues and TE671 cells, with the highest expression observed in the most RMS samples. Expression of p21 protein and apoptosis function were increased following treatment with 10058-F4, but no difference was observed in cell cycle progression. In conclusion, the present study indicated that c-Myc promotes RMS development by inhibiting apoptosis through repression of p21 transcription. Further studies will be required to evaluate c-Myc as a target for RMS clinical treatment.
\end{abstract}

Correspondence to: Dr Haijun Wang, Department of Pathology, School of Basic Medical Sciences, Xinxiang Medical University, 601 Jinsui Road, Hongqi, Xinxiang 453003, P.R. China

E-mail:wnavy200299@163.com

Dr Weixing Zhao, Department of Pathology, The First Affiliated Hospital of Xinxiang Medical University, 601 Jinsui Road, Xinxiang 453003, P.R. China

E-mail: weixingzhao2015@163.com

*Contributed equally

Keywords: rhabdomyosarcoma, c-Myc, p21, apoptosis, cell cycle

\section{Introduction}

Rhabdomyosarcoma, commonly referred to as RMS, is an exceedingly rare cancer type. It is categorized as a sarcoma, a cancer of connective tissues, in which the cancer cells are thought to be arise from skeletal muscle progenitors $(1,2)$. RMS tumors can occur at any age, but are most common in children under the age of $15(3,4)$. According to their clinical pathological morphology and genetic variation, RMS tumors can be divided into five subtypes $(5,6)$ : Botryoid RMS (BRMS), spindle cell RMS (SRMS), embryonal RMS (ERMS), alveolar RMS (ARMS), pleomorphic RMS (PRMS) and undifferentiated sarcoma (7,8). RMS tumor prognosis and outcome is highly correlated to these subtypes, suggesting that they exhibit different biological characteristics $(9,10)$.

$\mathrm{v}$-myc avian myelocytomatosis viral oncogene homolog (c-Myc) plays an essential role in cell development as a multifunctional effector of cell cycle progression, metabolism, proliferation, apoptosis, cellular transformation and tumorigenesis (11). A recent study indicated that c-Myc enhances expression of glutamine synthetase (GS), which is responsible for the synthesis of glutamine (Gln) from glutamate (Glu) and ammonia (12). Gln is a key molecule for nucleotide synthesis, protein synthesis, and the uptake of essential amino acids (EAA) that are required for tumor cell proliferation (12). Basal expression of cyclin dependent kinase inhibitor 1A (known as p21) in normal and cancer cells contributes to cell population heterogeneity in cell cycle progression and quiescent cell cycle states (13). High transcription of c-Myc mediates cell transition from G1 to $\mathrm{S}$ phase (14). Chen et al (15) demonstrated that p21 was repressed by c-Myc in hepatocellular carcinoma, via the ERK/c-Myc pathway. However, the role of c-Myc in RMS development remains unknown, and in particular, its relationship with $\mathrm{p} 21$.

In the present study, c-Myc protein expression was examined in RMS clinical samples of various subtypes and in the rhabdomyosarcoma cell line TE671. Furthermore, immunohistochemistry, reverse transcription-quantitative polymerase chain reaction (RT-qPCR) and western blot analyses were performed in order to explore the mechanism of c-Myc action 
in RMS. The present study revealed that $\mathrm{c}-\mathrm{Myc}$ promotes RMS tumor development by regulating p21 transcription, thus suggesting that c-Myc might be a suitable target for RMS clinical treatment.

\section{Materials and methods}

Tissue samples. All RMS clinical samples were provided by the First Affiliated Hospital of Xinxiang Medical University (Xinxiang, China) and Henan Cancer Hospital (Zhengzhou, China). In total, paraffin samples were prepared from 30 patients and were collected from 2002-2014, including 8 cases of ERMS, 10 cases of ARMS and 12 cases of PRMS. Normal skeletal muscle (the pectoralis major or pectoralis minor from surgical resected from five breast cancer patients who had not received any prior treatment) were used as controls. Parrafin section of $8 \mu \mathrm{m}$ thickness were used. The present study was approved by the Ethical Committee of Xinxiang Medical University (Xinxiang, China), and conformed to the Declaration of Helsinki and Good Clinical Practice guidelines. All patients participating in this study provided written informed consent.

Cell culture and reagents. The RMS cell line TE671 was purchased from American Type Culture Collection (Manassas, VA) and cultured in Dulbecco's modified Eagle's medium (Thermo Fisher Scientific, Inc., Waltham, MA, USA) supplemented with $10 \%$ fetal calf serum (catalog no. 10082147, Thermo Fisher Scientific, Inc.) and 1\% L-glutamine (cat no. 25030081, Thermo Fisher Scientific, Inc.). The c-Myc inhibitor 10058-F4 was obtained from Santa Cruz Biotechnology, Inc. (cat no. CAS 403811-55-2; Dallas, TX, USA). Cells were incubated at $37^{\circ} \mathrm{C}$ in a humidified atmosphere of $5 \% \mathrm{CO}_{2}$.

Immunohistochemistry of $c-M y c$. Expression of c-Myc in paraffin-embedded RMS tissues was detected using a monoclonal antibody to c-Myc (cat no. ab32072; Abcam, Cambridge, UK), as described previously (16). Immunostaining was carried out overnight at $4^{\circ} \mathrm{C}$ with the c-Myc antibody diluted 1:500, and then incubation with peroxidase complex was performed according to the manufacturer's instructions (catalog no. AR1022; Boster Biological Technology, Pleasanton, CA, USA). Image analysis was performed using a light microscope (Leica Microsystems GmbH, Wetzlar, Germany).

RT- $q P C R$. Total RNA was extracted using the RNeasy Mini kit (cat no. 74104; Qiagen GmbH, Hilden, Germany) according to the manufacturer's instructions. Total RNA $(1 \mu \mathrm{g})$ was used for cDNA synthesis using a First Strand cDNA Synthesis kit (cat no. KR104-01; Tiangen Biotech Co., Ltd., Beijing, China). Gene expression levels were analyzed by qPCR with SYBR Select Master Mix (cat no. 4472908; Thermo Fisher Scientific, Inc.) on a ABI7500 real-time PCR system (Applied Biosystems; Thermo Fisher Scientific, Inc.). Results were normalized to those obtained with human GAPDH primers as an internal reference control and were presented as the fold change in mRNA expression compared with the control group (17). The apoptosis detection kit was purchased from
Table I. The information of clinical RMS patients.

\begin{tabular}{|c|c|c|c|c|}
\hline Patients ID & Gender & Age & TNM staging & Type \\
\hline $1 \#$ & M & 8 & I & ERMS \\
\hline 2\# & $\mathrm{F}$ & 12 & II & ERMS \\
\hline $3 \#$ & M & 8 & II & ERMS \\
\hline $4 \#$ & M & 8 & II & ERMS \\
\hline $5 \#$ & $\mathrm{~F}$ & 14 & I & ERMS \\
\hline $6 \#$ & M & 11 & I & ERMS \\
\hline $7 \#$ & $\mathrm{~F}$ & 2 & II & ERMS \\
\hline $8 \#$ & M & 4 & II & ERMS \\
\hline 9\# & M & 23 & I & ARMS \\
\hline $10 \#$ & M & 6 & II & ARMS \\
\hline $11 \#$ & M & 11 & III & ARMS \\
\hline $12 \#$ & $\mathrm{~F}$ & 22 & III & ARMS \\
\hline $13 \#$ & M & 16 & II & ARMS \\
\hline $14 \#$ & M & 18 & II & ARMS \\
\hline $15 \#$ & $\mathrm{~F}$ & 14 & II & ARMS \\
\hline $16 \#$ & $\mathrm{~F}$ & 12 & II & ARMS \\
\hline $17 \#$ & M & 22 & II & ARMS \\
\hline $18 \#$ & M & 21 & III & ARMS \\
\hline $19 \#$ & $\mathrm{~F}$ & 67 & IV & PRMS \\
\hline $20 \#$ & $\mathrm{~F}$ & 48 & III & PRMS \\
\hline $21 \#$ & $\mathrm{~F}$ & 58 & III & PRMS \\
\hline $22 \#$ & M & 63 & IV & PRMS \\
\hline $23 \#$ & M & 49 & III & PRMS \\
\hline $24 \#$ & $\mathrm{~F}$ & 57 & III & PRMS \\
\hline $25 \#$ & M & 59 & II & PRMS \\
\hline $26 \#$ & M & 48 & III & PRMS \\
\hline $27 \#$ & $\mathrm{~F}$ & 57 & IV & PRMS \\
\hline $28 \#$ & M & 66 & III & PRMS \\
\hline $29 \#$ & $\mathrm{~F}$ & 47 & III & PRMS \\
\hline $30 \#$ & $\mathrm{~F}$ & 52 & III & PRMS \\
\hline
\end{tabular}

M, male; F, female; RMS, rhabdomyosarcoma; ERMS, embryonal RMS; ARMS, alveolar RMS; PRMS, pleomorphic RMS; TNM, tumor, nodes, metastasis.

Beyotime Institute of Biotechnology (cat no. C1065; Haimen, China). TE671 cells were treated with $60 \mu \mathrm{M} 10058-\mathrm{F} 4$ for $72 \mathrm{~h}$ and then harvested by centrifugation at $400 \mathrm{x}$ g for $5 \mathrm{~min}$ at room temperature. After washing twice with PBS, $5-10 \times 10^{4}$ cells were resuspended in $195 \mu$ l binding buffer, and then stained by adding $5 \mu \mathrm{l}$ Annexin V-PE for $15 \mathrm{~min}$ at room temperature, as per the kit instructions. Finally, the cells were analyzed for presence of apoptotic cells by flow cytometry (BD Biosciences). Each experiment was repeated at least three times.

Protein extraction and western blotting. Cells were lysed in cold immunoprecipitation buffer $(60 \mathrm{mM}$ Tris- $\mathrm{HCl}$ at $\mathrm{pH} 7.4,150 \mathrm{mM} \mathrm{NaCl}, 0.25 \%$ SDS and $1 \%$ Tergitol-type NP40) containing $10 \mathrm{mM} \mathrm{NaF}, 1 \mathrm{mM} \mathrm{Na}_{3} \mathrm{VO}_{4}$ and complete protease inhibitor (Roche Diagnostics, Basel, Switzerland) for $30 \mathrm{~min}$ on ice, and then centrifuged at $10,000 \mathrm{xg}$ at $4^{\circ} \mathrm{C}$. A 
A

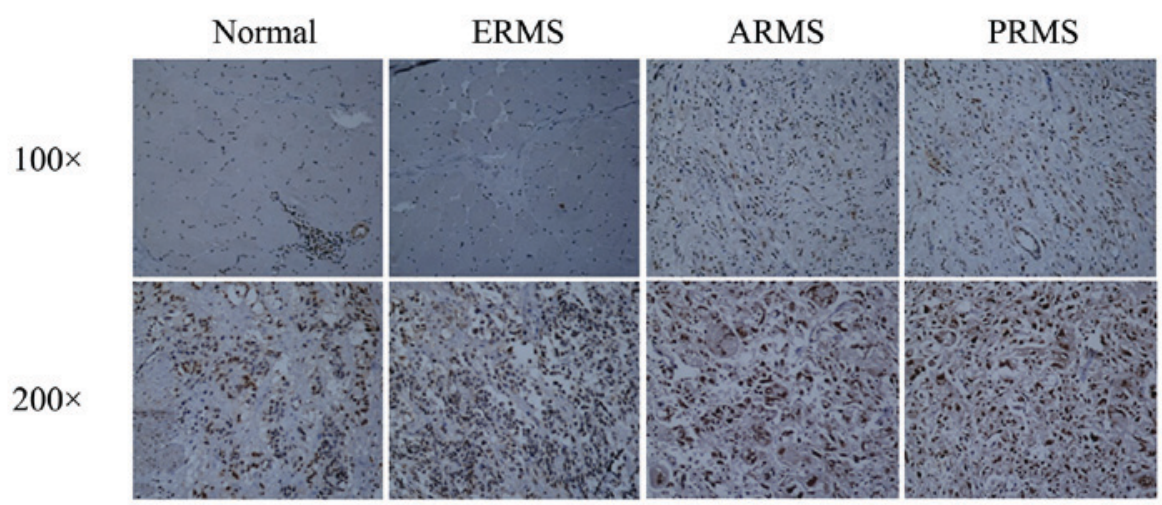

$\mathrm{B}$

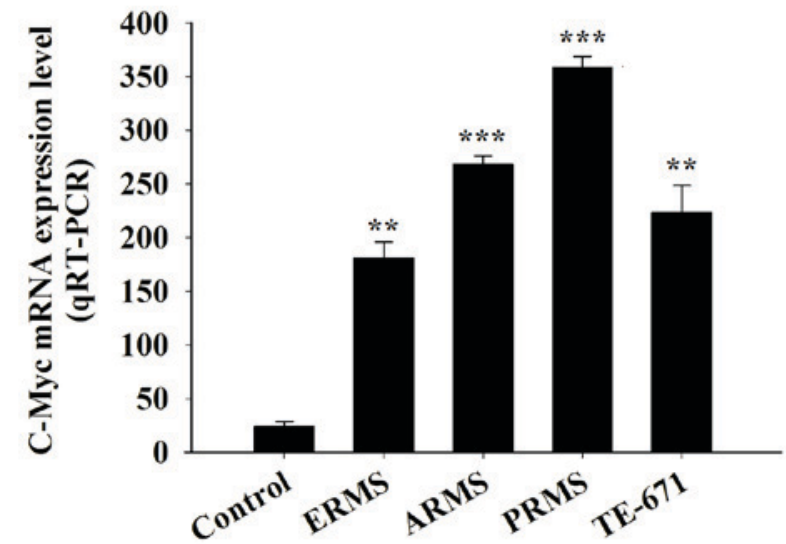

Figure 1. Immunochemistry detection of c-Myc expression in rhabdomyosarcoma tissues and TE671 cells. (A) Paraffin sections from normal skeletal muscle, ERMS, ARMS and PRMS patient tissues were stained for c-Myc protein. Representative images are depicted here from each group. Brown color denotes positive c-Myc staining. Upper panel, magnification x100; lower panel, magnification, x200. (B) c-Myc mRNA expression was analyzed in normal skeletal muscle, RMS clinical tissues and TE-671 cells by reverse transcription-quantitative polymerase chain reaction. Data are expressed as the mean + standard deviation. ${ }^{* *} \mathrm{P}<0.01$ and ${ }^{* * *} \mathrm{P}<0.001$ vs. control (normal skeletal muscle). ERMS, embryonal rhabdomyosarcoma; ARMS, alveolar rhabdomyosarcoma; PRMS, pleomorphic rhabdomyosarcoma.

bicinchoninic acid assay kit (cat no. P0010; Beyotime Institute of Biotechnology, Haimen, China) was used for protein quantification. A total of $40 \mu \mathrm{g}$ protein in each sample was separated by $12 \%$ SDS-PAGE and transferred onto polyvinylidene difluoride membranes. The membranes were blocked with 5\% non-fat milk for $20 \mathrm{~min}$ at room temperature, and then incubated with primary antibodies (dilution, 1:1,000) at $4{ }^{\circ} \mathrm{C}$ overnight, followed by incubation with the secondary antibody (dilution, 1:3,000) at room temperature for $30 \mathrm{~min}$. Protein bands were visualized using enhanced chemiluminescence with the ChemiDoc ${ }^{\mathrm{TM}}$ MP Imaging system (Bio-Rad Laboratories, Inc., Hercules, CA, USA). The protein bands from the blots were quantified with Image $\mathbf{J}$ software version 1.48 (National Institutes of Health, Bethesda, USA). Western blot analysis was performed using the following antibodies: c-Myc (cat no. ab32072; Abcam), p21 (cat no. ab109520; Abcam), GAPDH (cat no. sc-25778; Santa Cruz Biotechnology, Inc.) and goat anti-rabbit horseradish peroxidase-conjugated immunoglobulin G (cat no. sc-2004; Santa Cruz Biotechnology, Inc.).

Statistical analysis. The results were analyzed using SPSS 18.0 software (SPSS, Inc., Chicago, IL, USA). Each experiment was repeated at least three times. A two-tailed t-test was employed to estimate the significant difference between two independent groups, such as c-Myc transcription in RMS tissue vs. normal skeletal muscle. The results were presented as the mean \pm standard deviation. $\mathrm{P}<0.05$ was considered to indicate a statistically significant difference.

\section{Results}

Overexpression of c-Myc in RMS patient tissue and TE671 cells. To investigate the role of c-Myc in RMS, the expression level of c-Myc was assessed in RMS tissues and the RMS cell line TE671. ERMS (8 cases), ARMS (10 cases) and PRMS (12 cases) patient tissue samples were collected and processed by immunohistochemistry (IHC) for detection of c-Myc (Table I). Expression of c-Myc protein was variable in the different tissues (Fig. 1A). The c-Myc protein was significantly overexpressed in the ERMS, ARMS and PRMS patient tissue compared with the normal skeletal muscle tissues (Fig. 1A).

c-Myc mRNA expression levels were then assessed in RMS samples and TE671 cells (Fig. 1B). The results demonstrated that c-Myc mRNA was overexpressed in ERMS, ARMS, PRMS and TE671 cells compared with normal control $(\mathrm{P}<0.01$ for ERMS and TE-671 vs. control; $\mathrm{P}<0.001$ for ARMS and PRMS vs. control; Fig. 1B). These findings therefore suggest that c-Myc may promote the development of RMS. 
A

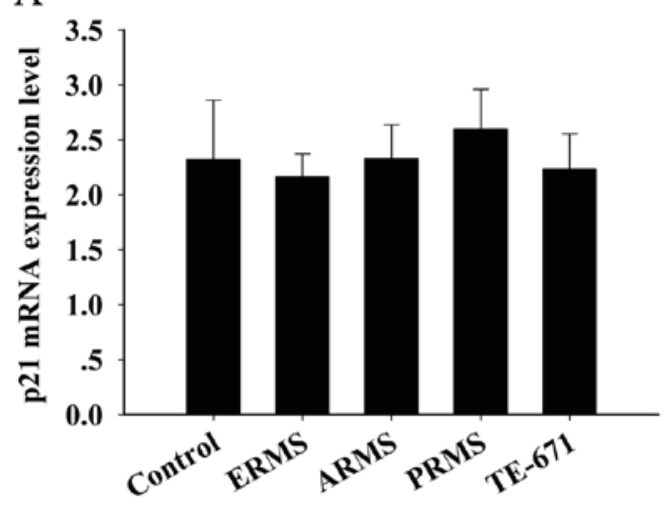

$\mathrm{C}$

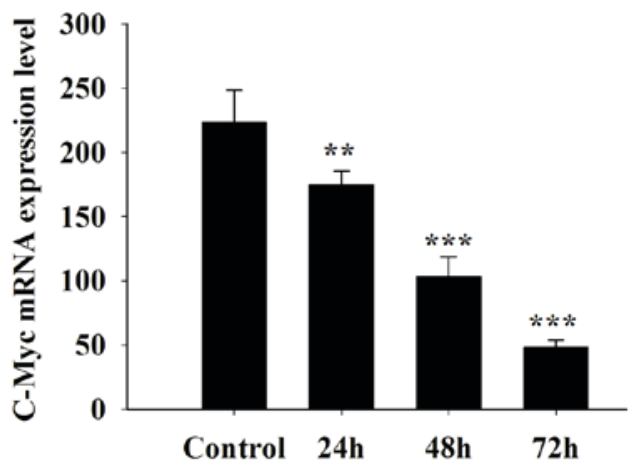

B

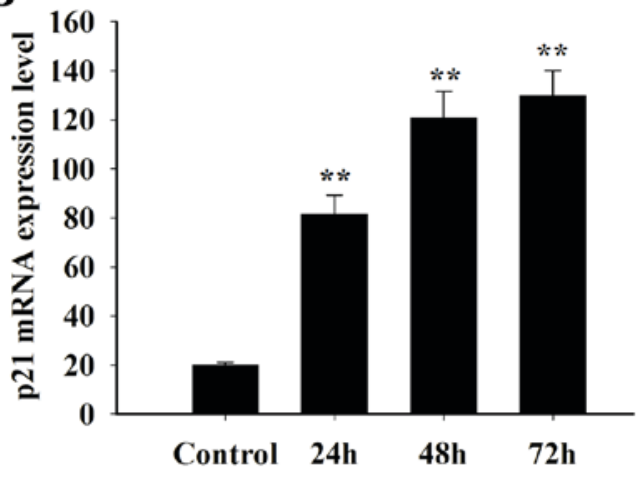

D

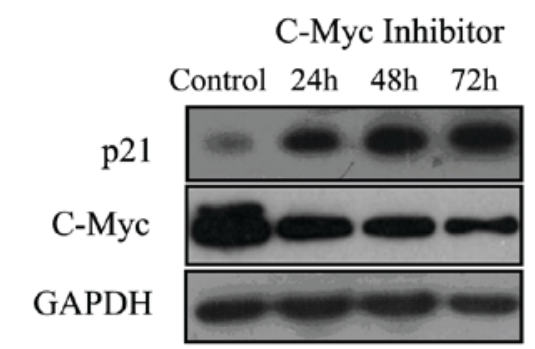

$\mathbf{E}$

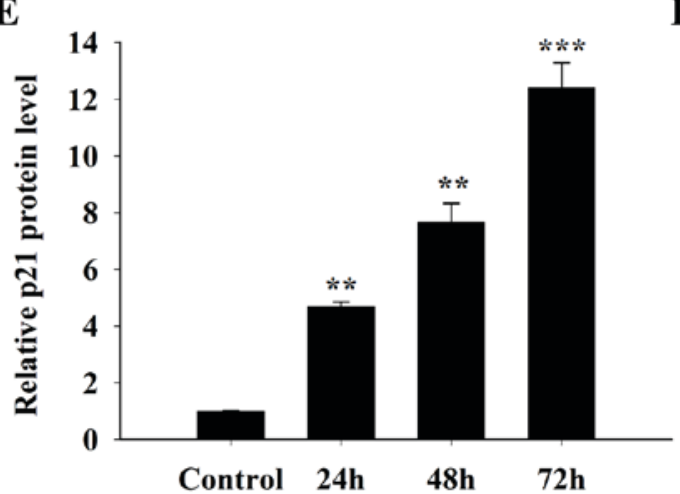

$\mathbf{F}$

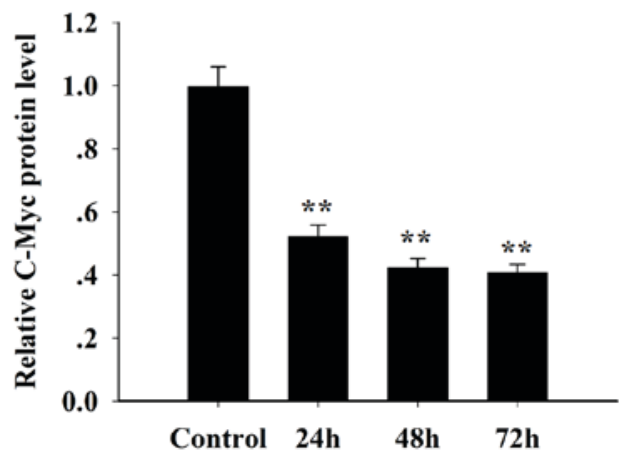

Figure 2. c-Myc promotes rhabdomyosarcoma development by regulating p21 transcription. (A) Endogenous p21 mRNA expression was evaluated in normal skeletal muscle (control), RMS tissues and TE671 cells by RT-qPCR relative to GAPDH. (B) p21 and (C) c-Myc mRNA expression was analyzed in TE671 cells untreated (control) or treated with $60 \mu \mathrm{M} \mathrm{c}-\mathrm{Myc}$ inhibitor 10058-F4 for 24, 48, and 72 h, by RT-qPCR. (D) Western blot analysis of p21 (upper panel) and c-Myc (lower panel) protein expression was performed in TE671 cells, untreated (control) or treated with $60 \mu \mathrm{M} \mathrm{10058-F4} \mathrm{for} \mathrm{24,} \mathrm{48,} \mathrm{and} \mathrm{72} \mathrm{h.} \mathrm{Densitometric}$ analysis of (E) relative p21 and (F) c-Myc protein expression levels. Data are expressed as the mean + standard deviation. ${ }^{* *} \mathrm{P}<0.01$ and ${ }^{* * * *} \mathrm{P}<0.001 \mathrm{vs}$. control. RT-qPCR, reverse transcription-quantitative polymerase chain reaction; ERMS, embryonal rhabdomyosarcoma; ARMS, alveolar rhabdomyosarcoma; PRMS, pleomorphic rhabdomyosarcoma.

c-Myc promotes RMS development by regulating p21 transcription. p21 is an important cell cycle inhibitor protein. Previous studies have demonstrated that p21 is important in inhibiting cancer cell growth and apoptosis $(18,19)$. Therefore, the hypothesis that c-Myc may promote RMS progression by regulating p21 expression was assessed.

Endogenous p21 mRNA expression levels in untreated RMS tissues and TE671 cells were detected (Fig. 2A). The results demonstrated that normal skeletal muscle tissue, RMS tissue and TE671 cells expressed similar levels of endogenous p21 mRNA, with no significant difference evident among these groups (P>0.05; Fig. 2A). Following treatment of TE671 cells with $60 \mu \mathrm{M}$ c-Myc inhibitor 10058-F4 for 24, 48 and $72 \mathrm{~h}$, p21 mRNA expression levels were significantly increased in a time-dependent manner compared with untreated control $(\mathrm{P}<0.01$; Fig. 2B). In contrast, in the same treatment conditions, c-Myc mRNA expression was significantly decreased in a time-dependent manner $(\mathrm{P}<0.01$ and $\mathrm{P}<0.001$, Fig. $2 \mathrm{C})$. Expression levels of p21 and c-Myc proteins were also assessed by western blot. p21 protein expression increased as time of treatment increased (Fig. 2D, upper panel), while c-Myc protein expression was significantly decreased compared with 
Table II. Effect of c-Myc inhibitor 10058-F4 on cell cycle.

The distribution of cell cycle $(\%)$

\begin{tabular}{lccc}
\cline { 2 - 4 } Groups & $\mathrm{G}_{1}$ phase & S phase & G2/M \\
\hline Control & $58.32 \pm 0.99$ & $26.95 \pm 1.07$ & $11.32 \pm 0.48$ \\
c-Myc inhibitor & $59.75 \pm 0.94$ & $28.04 \pm 1.27$ & $10.54 \pm 0.55$ \\
P-value & 0.357 & 0.546 & 0.347 \\
\hline
\end{tabular}

the untreated control (Fig. 2D, lower panel). Fig. 2E and F were the relative p21 and c-Myc protein levels respectively, according to Fig. 2C, as determined by densitometric analysis. In conclusion, c-Myc inhibition leads to increased expression of p21, which suggests that c-Myc may promote RMS development by repressing p21 transcription.

Effect of c-Myc inhibition on RMS cell apoptosis. TE671 cells were treated with $60 \mu \mathrm{M} 10058-\mathrm{F} 4$ for $72 \mathrm{~h}$, following which, apoptosis was measured by Annexin V-PE staining. As demonstrated in Fig. 3 the apoptosis rate of untreated cells (red line) was significantly lower than the inhibitor-treated cells (blue line). The result indicated that c-Myc inhibition leads to reduction of apoptosis in TE671 cells, thus suggesting that c-Myc plays an important role in maintaining RMS cell viability.

Effect of $c$-Myc inhibion on cell cycle. In the present study, $\mathrm{c}-\mathrm{Myc}$ was demonstrated to downregulate p21. Due to the function of p21 as a critical cell cycle kinase inhibitor, the role of c-Myc inhibition in TE671 cell cycle progression was assessed by flow cytometry (Fig. 4). No difference in the cell cycle analysis of untreated (Fig. 4A) vs. 10058-F4-treated cells (Fig. 4B) was evident. The result demonstrated that inhibition of c-Myc did not affect phase transition in TE671 cells, suggesting that c-Myc does not play a role in cell cycle regulation in RMS cells (Table II).

\section{Discussion}

Recently, new discoveries and molecular mechanisms about RMS development have emerged in large numbers. RMS has been linked to altered levels of several proliferation-related cytokines and cell signaling pathways $(20,21)$, and chromosomal abnormalities, such as PAX3-FKHR and PAX7-FKHR gene fusions, and heterozygous or homozygous gene deletions (8). Abnormal expression of specific genes, for example $11 \mathrm{p} 15.5$, is capable of promoting proliferation of RMS cells (9). In addition, a previous study has indicated that the proliferation markers PCNA and Ki-67 are overexpressed in RMS cells, suggesting that RMS cells have a high proliferation activity (22). In the present study, c-Myc expression was assessed in clinical RMS samples and TE671 RMS cells. In addition, the role of c-Myc in the regulation of p21 was examined.

c-Myc is localized to the cell nucleus, where transcription is not easily affected by external environmental factors. c-Myc, as a proliferation-promoting oncogene, interacts with other transcription factors to regulate the transcription of various

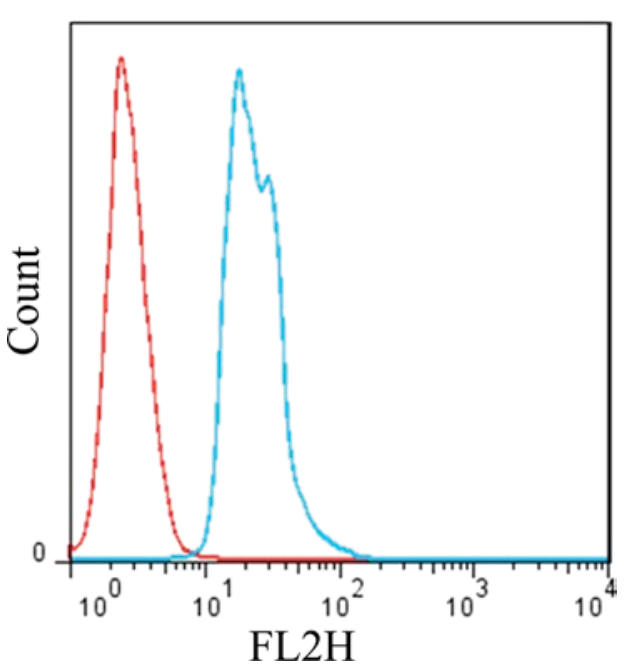

Figure 3. Effect of c-Myc inhibitor 10058-F4 on cell apoptosis. TE671 cells were treated with $60 \mu \mathrm{M} 10058-\mathrm{F} 4$ for $72 \mathrm{~h}$, and apoptosis was measured by Annexin V-PE staining and flow cytometry. Red line indicates the control untreated cells, blue line indicates the 10058-F4-treated cells.
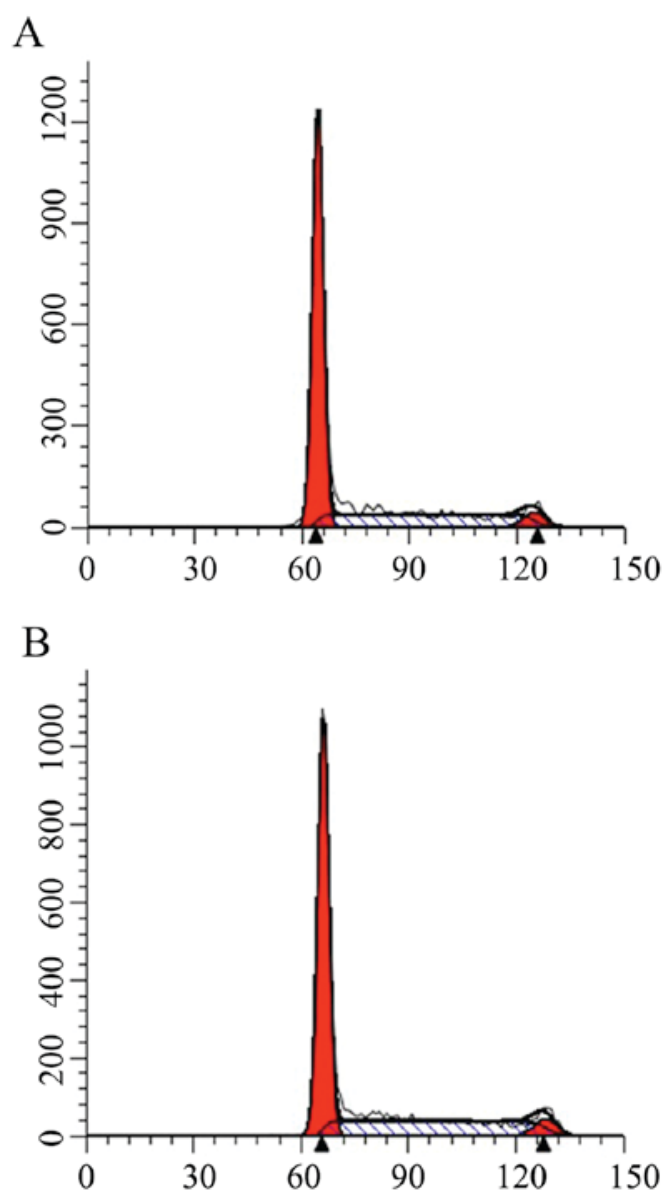

Figure 4. Effect of c-Myc inhibitor 10058-F4 on cell cycle. TE671 cells were treated with 10058-F4 for $72 \mathrm{~h}$ and cell cycle progression was analyzed by flow cytometry in (A) control untreated cells and (B) 10058-F4-treated cells.

genes (23). In the present study, c-Myc was discovered to be overexpressed in TE671 cells and in clinical RMS tissues. In addition, levels of c-Myc protein and mRNA expression were associated with malignancy of RMS $(24,25)$. Previous studies 
have demonstrated that expression of c-Myc in normal skeletal muscle and reactive hyperplasia tissues and lymphocytes of RMS exists in order to maintain normal physiological function (12).

The c-Myc inhibitor 10058-F4 is a small molecule compound that penetrates through the cell membrane and the nuclear membrane (13). The inhibitor specifically blocks the binding region of the c-Myc leucine zipper domain and results in c-Myc not recognizing the CACGTG motif sequence, thus inhibiting transcription of target genes (15). In the present study, p21 expression was demonstrated to be significantly increased following c-Myc inhibition in RMS cells. Due to the importance of p21 in cell apoptosis and the cell cycle, the effect of c-Myc inhibition on RMS cell behavior was further assessed. Apoptosis was significantly increased following 10058-F4 treatment, while cell cycle was not affected (Figs. 3 and 4 , respectively). p21 belongs to the cyclin-dependent kinase interacting protein/Kinase inhibitory protein family (26), and, together with tumor protein p53, contributes to the cell cycle G1 checkpoint (27). In the present study, no effect on cell cycle was observed following c-Myc inhibition, which suggests that synergistic action with another signaling pathway may be required for its role on cell proliferation.

c-Myc is an oncogene and p21 is a tumor suppressor gene (28). In the present study, c-Myc was demonstrated to promote RMS development by repressing p21 transcription. Further studies on the functions of c-Myc and p21 in RMS cells would greatly benefit future RMS research and therapy development.

\section{Acknowledgements}

We thank all the members of our laboratory for technical support and helpful discussion. This study was supported by a grant from the China National Foundation for Natural Science (grant no. 81602132) and Initiation Funding from Xingxiang Medical University (grant nos. XYBSKYZZ201512 and XYBSKYZZ201513).

\section{References}

1. Hettmer S, Li Z, Billin AN, Barr FG, Cornelison DD, Ehrlich AR, Guttridge DC, Hayes-Jordan A, Helman LJ, Houghton PJ, et al: Rhabdomyosarcoma: Current challenges and their implications for developing therapies. Cold Spring Harb Perspect Med 4: a025650, 2014

2. Parham DM: Correspondence re: Pathologic classification of rhabdomyosarcomas and correlations with molecular studies Mod Pathol 2001;14:506-14. Mod Pathol 14: 1068, 2001.

3. Ognjanovic S, Linabery AM, Charbonneau B and Ross JA: Trends in childhood rhabdomyosarcoma incidence and survival in the United States, 1975-2005. Cancer 115: 4218-4226, 2009.

4. Perez EA, Kassira N, Cheung MC, Koniaris LG, Neville HL and Sola JE: Rhabdomyosarcoma in children: A SEER population based study. J Surg Res 170: e243-e251, 2011.

5. Mercado GE, Xia SJ, Zhang C, Ahn EH, Gustafson DM, Laé M, Ladanyi M and Barr FG: Identification of PAX3-FKHR-regulated genes differentially expressed between alveolar and embryonal rhabdomyosarcoma: Focus on MYCN as a biologically relevant target. Genes Chromosomes Cancer 47: 510-520, 2008.

6. de Souza RR, Oliveira ID, Caran EM, Alves MT, Abib S and Toledo SR: Investigation of PAX3/7-FKHR fusion genes and IGF2 gene expression in rhabdomyosarcoma tumors. Growth Horm IGF Res 22: 245-249, 2012.

7. Byrne M, Wray J, Reinert B, Wu Y, Nickoloff J, Lee SH, Hromas R and Williamson E: Mechanisms of oncogenic chromosomal translocations. Ann N Y Acad Sci 1310: 89-97, 2014.
8. Meloni-Ehrig A,Smith B,Zgoda J,Greenberg J,Perdahl-WallaceE, Zaman S and Mowrey P: Translocation (2;8)(q35;q13): A recurrent abnormality in congenital embryonal rhabdomyosarcoma. Cancer genet cytogenet 191: 43-45, 2009.

9. EI Nadi E, Moussa EA, Zekri W, Taha H, Yones A, Zaghloul MS, El Wakeel M and Labib RM: Outcome of Rhabdomyosarcoma in First Year of Life: Children's Cancer Hospital 57357 Egypt. Sarcoma 2013: 439213, 2013.

10. Missiaglia E, Selfe J, Hamdi M, Williamson D, Schaaf G, Fang C, Koster J, Summersgill B, Messahel B, Versteeg R, et al: Genomic imbalances in rhabdomyosarcoma cell lines affect expression of genes frequently altered in primary tumors: An approach to identify candidate genes involved in tumor development. Genes, Chromosomes \& Cancer 48: 455-467, 2009.

11. Liu F, Dong X, Lv H, Xiu P, Li T, Wang F, Xu Z and Li J: Targeting hypoxia-inducible factor- $2 \alpha$ enhances sorafenib antitumor activity via $\beta$-catenin/C-Myc-dependent pathways in hepatocellular carcinoma. Oncol Lett 10: 778-784, 2015.

12. Bott AJ, Peng IC, Fan Y, Faubert B, Zhao L, Li J, Neidler S, Sun Y, Jaber N, Krokowski D, et al: Oncogenic Myc Induces Expression of Glutamine Synthetase through Promoter Demethylation. Cell Metab 22: 1068-1077, 2015.

13. Overton KW, Spencer SL, Noderer WL, Meyer T and Wang CL: Basal p21 controls population heterogeneity in cycling and quiescent cell cycle states. Proc Natl Acad Sci USA 111: E4386-E4393, 2014.

14. Deb-Basu D, Karlsson A, Li Q, Dang CV and Felsher DW: MYC can enforce cell cycle transit from G1 to S and G2 to S, but not mitotic cellular division, independent of p27 mediated inhibition of cyclin E/CDK2. Cell Cycle 5: 1348-1355, 2006.

15. Chen Y, Lin C, Liu Y and Jiang Y: HMGB1 promotes HCC progression partly by downregulating p21 via ERK/c-Myc pathway and upregulating MMP-2. Tumour Biol 37: 4399-4409, 2016.

16. Zhao LH and Liu HG: Immunohistochemical detection and clinicopathological significance of JARID1B/KDM5B and P16 expression in invasive ductal carcinoma of the breast. Genet Mol Res 14: 5417-5426, 2015.

17. Livak KJ and Schmittgen TD: Analysis of relative gene expression data using real-time quantitative PCR and the 2(-Delta Delta C(T)) method. Methods 25: 402-408, 2001.

18. Wang Y, Yuan Z, You C, Han J, Li H, Zhang Z and Yan H: Overexpression $\mathrm{p} 21 \mathrm{WAF} 1 / \mathrm{CIP} 1$ in suppressing retinal pigment epithelial cells and progression of proliferative vitreoretinopathy via inhibition CDK2 and cyclin E. BMC Ophthalmology 14: 144, 2014.

19. Chen A, Huang X, Xue Z, Cao D, Huang K, Chen J, Pan Y and Gao Y: The Role of p21 in Apoptosis, Proliferation, Cell Cycle Arrest and Antioxidant Activity in UVB-Irradiated Human HaCaT Keratinocytes. Med Sci Monit Basic Res 21: 86-95, 2015.

20. Anderson J, Ramsay A, Gould S and Pritchard-Jones K: PAX3-FKHR induces morphological change and enhances cellular proliferation and invasion in rhabdomyosarcoma. Am J Pathol 159: 1089-1096, 2001.

21. Li F, Shi W, Capurro M and Filmus J: Glypican-5 stimulates rhabdomyosarcoma cell proliferation by activating Hedgehog signaling. J Cell Biol 192: 691-704, 2011.

22. Andrade CR, Takahama Junior A, Nishimoto IN, Kowalski LP and Lopes MA: Rhabdomyosarcoma of the head and neck: A clinicopathological and immunohistochemical analysis of 29 cases. Braz Dent J 21: 68-73, 2010.

23. Conacci-Sorrell M, McFerrin L and Eisenman RN: An overview of MYC and its interactome. Cold Spring Harbor perspectives in medicine 4: a014357, 2014.

24. Marampon F, Ciccarelli C and Zani BM: Down-regulation of c-Myc following MEK/ERK inhibition halts the expression of malignant phenotype in rhabdomyosarcoma and in non muscle-derived human tumors. Molecular Cancer 5: 31, 2006.

25. Kouraklis G, Triche TJ, Wesley R and Tsokos M: Myc oncogene expression and nude mouse tumorigenicity and metastasis formation are higher in alveolar than embryonal rhabdomyosarcoma cell lines. Pediatr Res 45: 552-558, 1999.

26. Abbas T and Dutta A: p21 in cancer: Intricate networks and multiple activities. Nat Rev Cancer 9: 400-414, 2009.

27. Yousefi B, Rahmati M and Ahmadi Y: The roles of p53R2 in cancer progression based on the new function of mutant p53 and cytoplasmic p21. Life Sci 99: 14-17, 2014.

28. Ohkoshi S, Yano M and Matsuda Y: Oncogenic role of p21 in hepatocarcinogenesis suggests a new treatment strategy. World J Gastroenterol 21: 12150-12156, 2015. 